\title{
THE EFFECT OF FRAGMENTATION AND INTENSIVE MANAGEMENT ON CARABID BEETLES IN CONIFEROUS FOREST
}

\author{
Do, Y. ${ }^{1,2}-$ JoO, G.J. ${ }^{1 *}$ \\ ${ }^{I}$ Department of Biological Sciences, Pusan National University \\ Jangjeon-dong, Geumjeong-gu, Busan 609-735, Republic of Korea \\ (phone: + 82-51-510-2258; fax: +82-51-581-0172) \\ ${ }^{2}$ Institute of Environmental Technology and Industry \\ *Corresponding author \\ e-mail: gjjoo@pusan.ac.kr;doy@pusan.ac.kr \\ (Received 21 $1^{\text {st }}$ October 2011; accepted $2^{\text {nd }}$ September 2013)
}

\begin{abstract}
We studied the effects of forest fragmentation and management practices on carabid beetle (Coleoptera: Carabidae) assemblages in the Japanese red pine forests of Naju City, South Korea. A total of 2,058 carabid individuals, representing 15 species, were collected by pitfall trapping from May to September 2010 in three forest types: native forest (relatively undisturbed forest), managed forest (planted trees with clear-cutting of the herb layer), and forest patch (fragmented forest). We showed that the different forest types differed significantly in terms of their carabid assemblages. The managed forest had the most distinct assemblage, with a lower species richness and abundance than the other two forest types. Although forest fragmentation did not significantly affect the species richness of carabid beetle assemblages, the abundance of some carabid beetles (forest specialists and large-sized species) was significantly altered by forest fragmentation and intensive forest management. Sub-tree layer and herb cover were the strongest environmental variables determining the carabid assemblage composition. Forest fragmentation is an inevitable change in landscape structure, particularly in urbanized and pre-urban areas, and it constitutes a threat to biodiversity through landscape homogenization. Therefore, it is necessary to identify appropriate management practices, designed to minimize the damage caused by the loss and modification of natural habitats, together with maintenance and enhancement of the biodiversity in urban areas.
\end{abstract}

Keywords: forest fragmentation, intensive management practice, understorey vegetation, pine forest, carabid beetle

\section{Introduction}

Habitat loss and fragmentation are major factors influencing species distribution and diversity across landscapes (Didham et al., 1996; Fahrig, 2003). Forest fragmentation is moderately correlated with the gradient of urbanization pressure. Forest patches in an urbanized area can be viewed as stepping stones between urban forests and native forests in the adjacent forest landscape. The ecological values of forest fragments and the management to maintain and enhance their biodiversity and amenity value are more important in urbanized and pre-urban areas than in the rural landscape (Pirnat, 2001; Tyrväinen, et al., 2003).

Forest management practices also affect soil properties, litter accumulation rate, understorey structure, and the vegetation composition. Furthermore, intensive forest management regimes can influence ecological processes such as nutrient cycling, vegetation regeneration, and predation rate. Changes in the forest environment affect species either positively or negatively, depending on their habitat requirements (Waring 
and Schlesinger, 1985; Kimmins, 1997). Therefore, to achieve the stated goals, the choice of suitable management practices must be decided on a case-bycase basis, depending on the landscape type and the management objectives.

The aim of this study was to investigate the effects of forest fragmentation and management regime upon carabid beetles. Carabid beetles are an exceptionally useful study community for examining the effects of habitat change, such as those due forest fragmentation and management practices, because they are diverse and abundant, their ecology and systematics are relatively well known (Lövei and Sunderland, 1996) and they seem to be highly sensitive to forest fragmentation and management (Magura, et al. 2001; Niemelä, 2001; Lövei et al., 2006; Raino and Niemelä, 2003; Pearce and Venier, 2006).

In this study, we tested the following predictions: (1) there is no significant difference in the carabid assemblages of native forest, managed forest, and forest fragment sites, regarding species richness, abundance, and community composition; and (2) forest specialist and large-sized carabid species should be more sensitive to artificial forest modification. We also investigated how changes in carabid assemblages and environmental variables affect the species community.

\section{Materials and methods}

\section{Study sites}

Nine sites in three forest types were selected in order to examine the effects of forest fragmentation and management: three in native forest, three in managed forest, and three in forest fragments (Fig. 1).

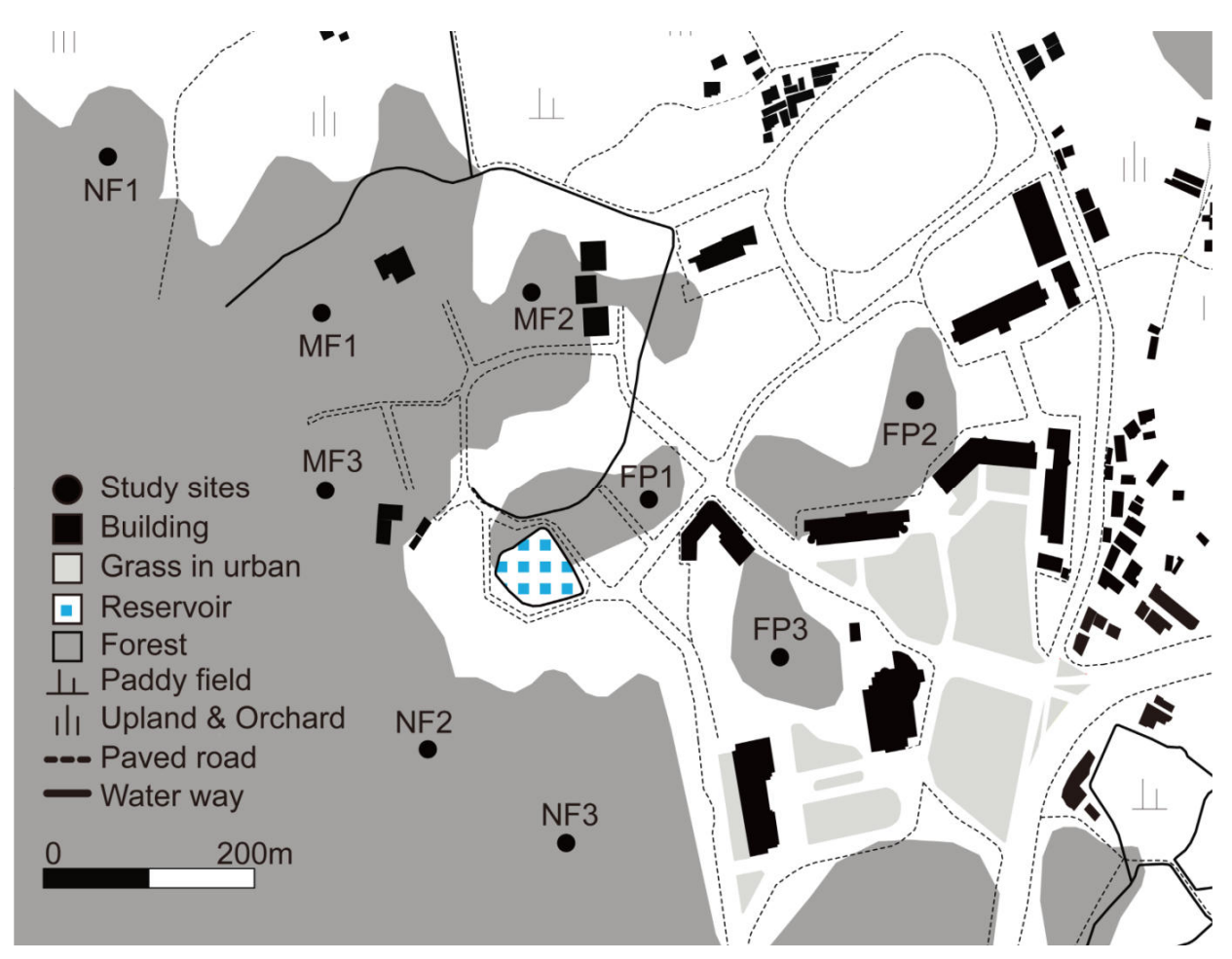

Figure 1. Location of the sampling sites 
All sampling sites were dominated by Pinus densiflora Siebold \& Zucc. The native forest sites are relatively undisturbed since they are protected as part of a military area. These areas have dense herbaceous vegetation and a shrub layer dominated by Trachelospermum asiaticum var. intermedium Nakai, Smilax china L., Pueraria lobata (Willd.) Ohwi, Quercus mccormickii Carruth, $Q$. acutissima Carruth, and Rhododendron mucronulatum var. ciliatum Nakai. The managed forest sites adjoining the native forest are planted with $P$. densiflora. They are characterized by dense herbaceous vegetation dominated by Oplismenus undulatifolius (Ard.) P. Beauv. var. undulatifolius, although the shrub layer is sparse. The weeds and grass in the managed forest sites are mowed approximately five times a year, specifically in the summer and autumn. The forest fragments are located in the center of an urbanized area and became fragmented in the early 1990s as a consequence infrastructure development. They have vegetation very similar to that of the native forest sites.

\section{Sampling methods}

Carabid beetles were sampled by pitfall trapping. We placed four pitfall traps $(90$ $\mathrm{mm}$ diameter, $100 \mathrm{~mm}$ deep plastic cups) at least $10 \mathrm{~m}$ apart in an irregular line at each study site. Each cup contained approximately $50 \mathrm{ml}$ of a $4 \%$ formalin solution to kill and preserve the trapped carabid beetles. The traps were emptied on a monthly basis during one growing season (May to September 2010).

Soil properties and vegetation structures were measured close to the traps (Table 1). The soils were further characterized by measuring the $\mathrm{pH}$ and organic matter content. Soil $\mathrm{pH}$ was measured using a bench top probe after mixing the soil with distilled water (1:5 ratio, w/v) and filtering the extract (Whatman No. 44 filter paper). Organic matter content was estimated from loss on ignition by burning $1 \mathrm{~g}$ samples of the sieved dried soil at $550^{\circ} \mathrm{C}$ for 2 hours.

Table 1. Forest type characteristics

\begin{tabular}{c|c|c|c|c|c|c|c|c}
\hline \multirow{2}{*}{ Forest type } & \multirow{2}{*}{ Abbr. } & \multirow{2}{*}{$\begin{array}{c}\text { Area } \\
\text { (ha) }\end{array}$} & \multirow{2}{*}{$\begin{array}{c}\text { Altitude } \\
(\mathbf{m})\end{array}$} & \multicolumn{5}{|c}{$\begin{array}{c}\text { Vegetation structure } \\
\text { (Coverage \%) }\end{array}$} \\
\cline { 5 - 9 } & & & & T1 & T2 & S & H & VC \\
\hline \multirow{3}{*}{ Natural forest } & NF1 & & 127 & 95 & 20 & 70 & 80 & 24 \\
& NF2 & & 125 & 95 & 25 & 70 & 85 & 22 \\
& NF3 & & 65 & 90 & 20 & 70 & 80 & 20 \\
\hline \multirow{3}{*}{ Managed forest } & MF1 & 1.87 & 65 & 80 & 0 & 5 & 80 & 10 \\
& MF2 & 1.11 & 50 & 75 & 5 & 0 & 80 & 9 \\
& MF3 & 1.95 & 80 & 80 & 0 & 0 & 85 & 6 \\
\hline \multirow{3}{*}{ Forest patch } & FP1 & 1.40 & 52 & 90 & 35 & 70 & 80 & 19 \\
& FP2 & 2.41 & 43 & 90 & 35 & 75 & 80 & 18 \\
& FP3 & 1.05 & 44 & 95 & 30 & 70 & 85 & 16 \\
\hline
\end{tabular}

$\dagger$ Abbr., abbreviation; *Vegetation structure: $\mathrm{T} 1=$ tree layer, $\mathrm{T} 2=$ sub-tree layer, $\mathrm{S}=$ shrub layer, $\mathrm{H}=$ herb layer, $\mathrm{VC}=$ number of vegetation community

The vegetation structure of the each forest type was described by estimating the proportional cover of the tree layer, sub-tree layer, and grass layer plant species at each site. Vertical stand structure was assessed using a visual cover method that recognizes four vegetation strata: herb layer $(10 \mathrm{~cm}-1 \mathrm{~m})$, shrub layer $(1-2 \mathrm{~m})$, sub-tree layer $(2-5$ $\mathrm{m})$, and tree layer $(5-10 \mathrm{~m})$. Taller vegetation consisting of tree, sub-trees, and shrubs was sampled in $10 \mathrm{~m} \times 10 \mathrm{~m}$ plots, and smaller vegetation consisting of herbs was 
sampled in $1 \mathrm{~m} \times 1 \mathrm{~m}$ plots. The number of plant communities was identified by the different dominant plant species in each plot.

Carabid beetles were divided into two ecological groups according to their habitat preference (Do et al., 2002; 2007; 2011; Park and Paik, 2001; Working Group for Biological Indicator Ground Beetles Database, Japan, 2011): forest species and nonforest species. Further data on body size were obtained from the Biological Indicator Ground Beetles Database, Japan (2011).

\section{Data analysis}

Differences in the carabid assemblages among the forest types were examined by analyzing the differences in the numbers of carabid species and in the number of individuals of each species caught in each forest type by one-way ANOVAs. In order to identify any differences in the catches, repeated-measures multivariate ANOVA on the effects of species, habitat preference, and body size on carabid abundance within forest types was carried out on the catch data from each forest type. The analysis was performed using the R statistical software package (implemented in the "Rcmdr" package; Fox, 2005).

Detrended correspondence analysis (DCA) was used to ordinate the land use type and to differentiate carabid beetle assemblages (Jongman et al., 1995). Canonical correspondence analysis (CCA) was used to identify the species-environment relationships and to determine the relative importance of environmental variables to species assemblages (Jongman et al., 1995; ter Braak and Ŝmilauer, 2002). The significance of these environmental factors in structuring the carabid communities was determined with a forward selection procedure using Monte Carlo simulation (499 permutations). This analysis was undertaken using PC-ORD version 6 (McCune and Grace, 2002).

\section{Results}

\section{Carabid diversity of each forest type}

A total of 2,058 individuals representing 15 carabid species were collected: 1,058 individuals belonging to 15 species were captured in the native forest, 740 individuals belonging to 15 species in the forest fragments, and 260 individuals belonging to 10 species in the managed forest (Table 2). Dolichus halensis, Synuchus nitidus, Anisodactylus punctatipennis, Synuchus cycloderus, and Carabus jankowskii were classified as dominant; the number of collected individuals of each of these species accounted for more than $10 \%$ of the total abundance. The four most abundant species represented $50.4 \%$ of the total individuals.

ANOVA revealed that carabid richness differed significantly among the different forest types $(\mathrm{F}=45.6, \mathrm{P}<0.001 ;$ Fig. 2). A Turkey-type posteriori test indicated that the carabids collected in both the native forest and in the forest fragments were significantly more diverse than those collected in the managed forest $(\mathrm{P}<0.001)$. The difference in the number of species caught in the native forest and in the forest fragments was not significant.

Carabid abundance was also significantly different among forest types ( $\mathrm{F}=17.08, \mathrm{P}$ $<0.01)$. Significantly more carabid beetles were sampled in both the native forest and 
forest fragments than in the managed forest $(\mathrm{P}<0.001)$. The difference in the number of individuals between the native forest and the forest fragments was not significant.

Table 2. Carabid inventory in different forest types

\begin{tabular}{|c|c|c|c|c|c|}
\hline Species & NF & MF & FP & Habitat type $^{\dagger}$ & Body size \\
\hline Anisodactylus punctatipennis & 140 & 25 & 81 & $\mathrm{~N}$ & $\mathrm{~S}$ \\
\hline Chlaenius bioculatus & 30 & 0 & 11 & $\mathrm{~N}$ & M \\
\hline Chlaenius micans & 22 & 0 & 17 & $\mathrm{~N}$ & M \\
\hline Chlaenius ocreatus & 21 & 0 & 5 & $\mathrm{~N}$ & M \\
\hline Chlaenius pallipes & 7 & 0 & 7 & $\mathrm{~N}$ & M \\
\hline Carabus jankowskii & 104 & 11 & 76 & $\mathrm{~F}$ & $\mathrm{~L}$ \\
\hline Dolichus halensis & 164 & 37 & 157 & $\mathrm{~N}$ & M \\
\hline Harpalus chalcentus & 11 & 45 & 36 & $\mathrm{~N}$ & M \\
\hline Harpalus sinicus & 23 & 0 & 5 & $\mathrm{~N}$ & M \\
\hline Nebria chinensis & 49 & 2 & 8 & $\mathrm{~F}$ & M \\
\hline Nebria coreica & 55 & 15 & 25 & $\mathrm{~F}$ & M \\
\hline Pterostichus fortis & 89 & 11 & 52 & $\mathrm{~N}$ & $\mathrm{~L}$ \\
\hline Synuchus arcuaticollis & 84 & 47 & 46 & $\mathrm{~F}$ & S \\
\hline Synuchus cycloderus & 116 & 46 & 110 & $\mathrm{~F}$ & M \\
\hline Synuchus nitidus & 143 & 21 & 104 & $\mathrm{~F}$ & M \\
\hline No. individuals & 1058 & 260 & 740 & & \\
\hline No. species & 15 & 10 & 15 & & \\
\hline No. forest species & 6 & 6 & 6 & 6 & \\
\hline No. non-forest species & 9 & 4 & 9 & 9 & \\
\hline
\end{tabular}

$\dagger \mathrm{S}<10 \mathrm{~mm} \leq \mathrm{M}<20 \mathrm{~mm} \leq \mathrm{L}$ for mean body length. *Provisional categorization of species based on habitat preference: F, forest species; N, non-forest species (ref. Do et al., 2006; Do et al, 2007; Do et al, 2011)

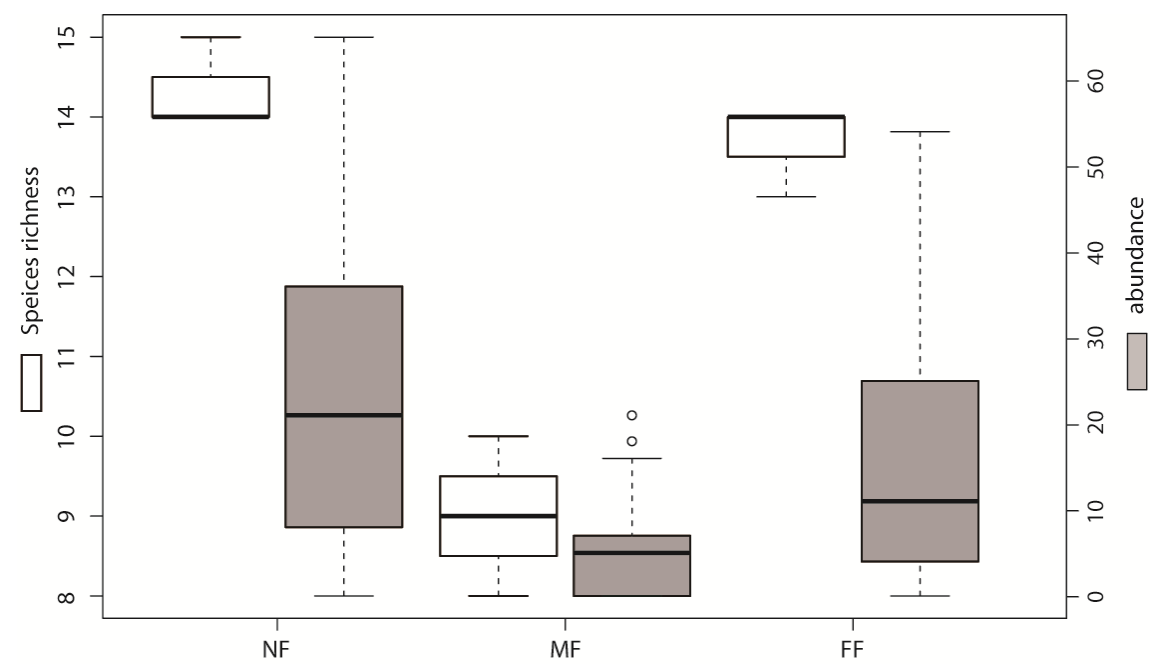

Figure 2. The species richness and abundance of carabid beetles caught in different forest types ( $N F=$ native forest $; M F=$ managed forest $; F=$ forest fragment)

\section{Effect of forest fragmentation and management on carabid species}

Of the total 15 species captured, six are forest species and the remaining nine are non-forest species (cf. Table 2). In the native forest and the forest fragments, all six forest species were caught. The species richness in both native forest and the forest 
fragments was significantly higher than that in the managed forest, in which only four forest species were caught $(\mathrm{F}=10.08, \mathrm{P}=0.003)$. However, there were no statistically significant differences in forest carabid abundance within forest types $(\mathrm{F}=0.61, \mathrm{P}=$ 0.56; Table 3).

Two of the species recorded in all study sites are small-sized carabid beetles, 11 are medium-sized species, and two are large-sized species (cf. Table 2). There was a significant interaction among carabid richness $(\mathrm{F}=46.50, \mathrm{P}<0.001)$ and abundance $(\mathrm{F}$ $=22.85, \mathrm{P}<0.001)($ Table 3).

Table 3. Canonical correspondence analysis correlation values of the environmental variables with the first two axes statistical significance values for the Monte Carlo permutation tests for each variable

\begin{tabular}{|c|c|c|c|c|}
\hline Factors & df & MS & $\mathbf{F}$ & $\mathbf{P}$ \\
\hline Richness & & & & \\
\hline Forest type (FT) & 2 & 11.06 & 16.58 & $<0.001$ \\
\hline Habitat type (HT) & 1 & 5.55 & 8.33 & 0.014 \\
\hline $\mathrm{FT}: \mathrm{HT}$ & 2 & 6.72 & 10.08 & 0.003 \\
\hline Error & 12 & 0.67 & & \\
\hline Abundance & & & & \\
\hline Forest type (FT) & 2 & 26123.50 & 160.43 & $<0.001$ \\
\hline Habitat type (HT) & 1 & 329.00 & 2.02 & 0.18 \\
\hline $\mathrm{FT}: \mathrm{HT}$ & 2 & 99.00 & 0.61 & 0.56 \\
\hline Error & 12 & 162.83 & & \\
\hline Richness & & & & \\
\hline Forest types (FT) & 2 & 8.44 & 57.00 & $<0.001$ \\
\hline Size $(\mathrm{S})$ & 2 & 427.88 & 855.75 & $<0.001$ \\
\hline $\mathrm{FT}: \mathrm{S}$ & 4 & 11.62 & 46.50 & $<0.001$ \\
\hline Error & 18 & 0.15 & & \\
\hline Abundance & & & & \\
\hline Forest types (FT) & 2 & 17881.00 & 132.49 & $<0.001$ \\
\hline Size $(\mathrm{S})$ & 2 & 31047.00 & 230.04 & $<0.001$ \\
\hline $\mathrm{FT}: \mathrm{S}$ & 4 & 3084.00 & 22.85 & $<0.001$ \\
\hline Error & 18 & 134.94 & & \\
\hline
\end{tabular}

\section{Carabid assemblage composition and forest type}

The DCA sampling scatter (total inertia, 0.19; eigenvalues for axes 1 and 2 were 0.11 and 0.018 , respectively, together explaining $65.0 \%$ of the variation of the carabid dataset) showed that native forest, managed forest, and forest fragments formed three distinct groups along axis 1 (Fig. 3). Ordination axis 1 was significantly negatively correlated with the number of vegetation communities, and with the coverages of shrubs, tree layer, and sub-tree layer $\left(\mathrm{r}_{\mathrm{s}}>-0.9, \mathrm{P}>0.01\right)$ in the environmental matrix.

Axis 1 scores in the plots for each forest type were significantly different $(\mathrm{F}=$ 164.55, $\mathrm{P}<0.001$ ), indicating that the carabid assemblages in each forest type are different. In addition, the ordination plot clearly shows that the carabid assemblages in native forest sites are quite distinct from those in the forest fragments despite these environments being dominated by similar plant communities $(\mathrm{P}=0.0037$; Fig. 3$)$. 


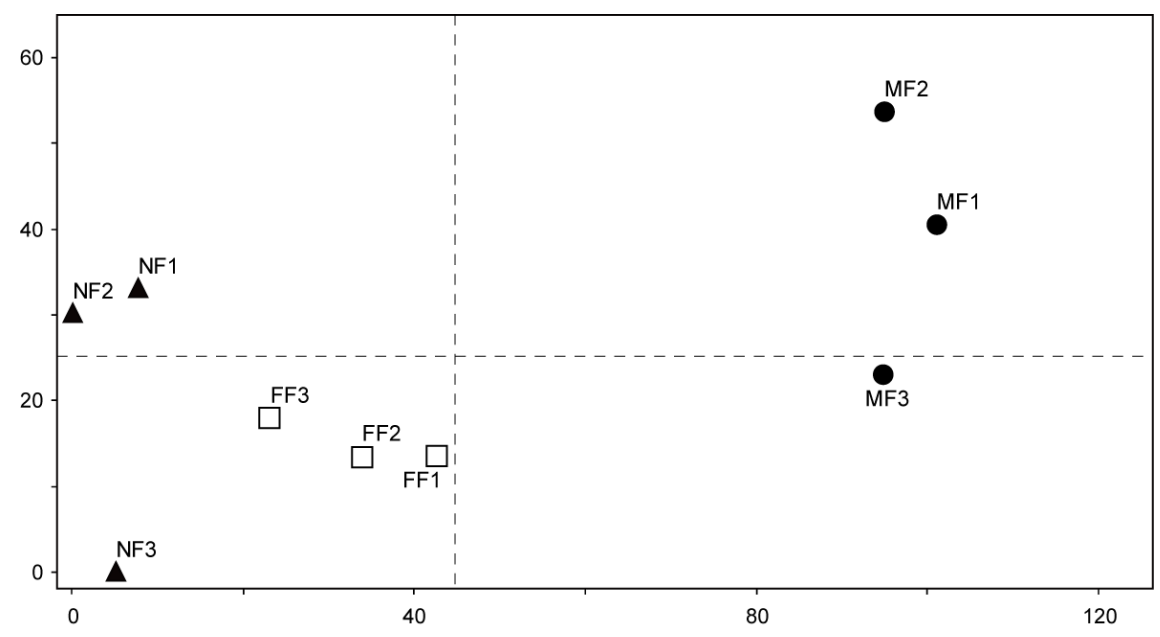

Figure 3. Detrended correspondence analysis for carabid species and site (NF=native forest; $M F=$ managed forest; $F F=$ forest fragment; species abbreviation=ref. Table 1)

\section{Relationship between species composition and environmental gradients}

Triplots carried out using the CCA ordination method represent environmental variables, sampling sites, and species in relation to their scores on the two main axes of ordination (Fig. 4). On the basis of the species-environment data, the eigenvalues of axes 1 and 2 were 0.107 and 0.028 , respectively. The cumulative percentage of variance explained by the first two axes accounted for $70.4 \%$ (55.7\% and $14.7 \%$, respectively, for axes 1 and 2) of species data and $75.4 \%$ (59.6\% and $15.8 \%$, respectively, for axes 1 and 2) of species-environment relationships. A Monte Carlo permutation test showed that axis 1 contributed significantly to the explained variance $(\mathrm{P}=0.002)$.

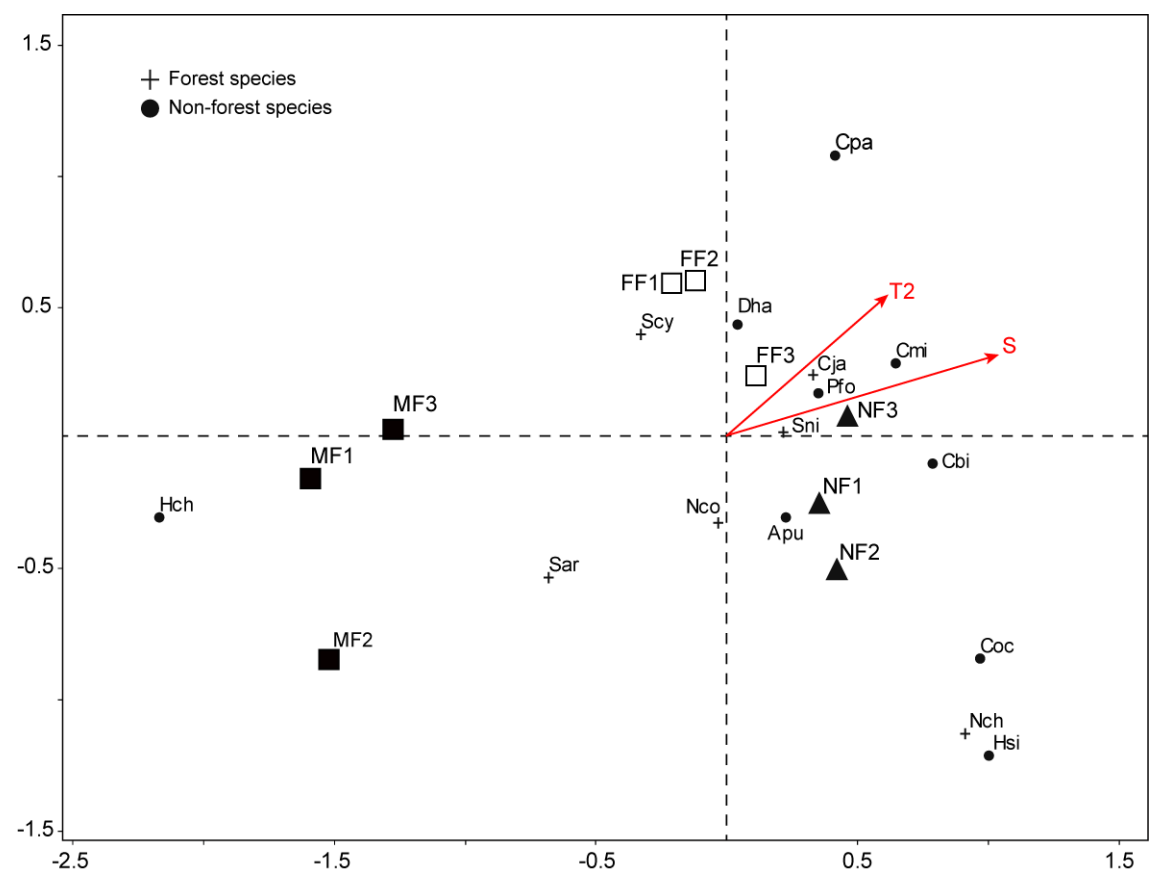

Figure 4. Canonical correspondence analysis for carabid species and environmental variables. (Environmental variable abbreviations $=$ ref. Table 2) 
For carabids, the environmental variables determining the gradients in the CCA diagrams, according to their correlations with the axes, were coverage of the tree layer and shrubs for axis 1 and coverage of the sub-tree layer for axis 2. These two significant environmental variables (coverage of the sub-tree layer and shrubs) were subsequently fitted as covariates to account for this variation, and the model was rerun as a partial CCA constrained by forest type.

Two principal groups were detected: tree-shrub sites (native forest and forest fragments) and non-shrub sites (managed forest). Tree-shrub sites contained forest generalists, such as Chlaenius micans, Pterostichus fortis, and Harpalus sinicus, and the forest specialists $S$. nitidus and $C$. jankowskii. The carabids $C$. jankowskii, $S$. nitidus, $P$. fortis, and $C$. micans, which include large-sized species and those highly sensitive to coverage of the sub-tree layer and shrubs, are well adapted to the micro-environmental conditions of the native forest area. Non-shrub sites contained generalist species, such as Dolichus halensis, Anicsodactylus punctatipennis, and $H$. chalcentus, and the forest specialist species $S$. arcuaticollis, $S$. cycloderus, and Nebria coreica. In these sites, two small-sized species seemed negatively sensitive to shrub cover.

Table 4. Results from a repeated measures analysis of variance (repeated ANOVA) on the factors affecting the carabid assemblages

\begin{tabular}{c|c|c|c|c}
\hline \multirow{2}{*}{ Environmental variables } & \multicolumn{4}{|c}{ Correlation values } \\
\cline { 2 - 5 } & Axis 1 & Axis 2 & F & P values \\
\hline pH (pH) & 0.318 & -0.017 & 1.26 & 0.07 \\
Soil organic matter content (OM) & 0.573 & 0.473 & 0.56 & 0.62 \\
Tree layer (T1) & 0.110 & -0.327 & 0.90 & 0.47 \\
Sub-tree layer (T2) & 0.899 & 0.343 & 2.50 & 0.03 \\
Shrub layer (S) & 0.537 & 0.612 & 6.26 & 0.006 \\
Herb layer (H) & 0.896 & 0.018 & 5.06 & 0.74 \\
Number of vegetation community (VC) & 0.885 & -0.125 & 1.26 & 0.29 \\
\hline
\end{tabular}

\section{Discussion}

We showed that both forest fragmentation and an intensive management regime can affect carabid beetle species composition. Our results indicate that (1) there was no significant difference in species richness between native forest and forest fragments, (2) the total number of sampled individuals was smaller in forest fragments than in the native forest, (3) intensive forest management significantly reduced the carabid species richness and abundance, (4) some forest species declined but their richness and abundance were not significantly associated with forest fragmentation and management practice, and (5) large-sized and small-sized carabid beetles were more negatively affected by forest habitat modification.

A major component of the anthropogenic impact upon forests is habitat fragmentation (Andrén, 1997; Hanski, 1999). However, there are several factors, including fragment size, surrounding landscape, vegetation structure, and ecological character (e.g., dispersal ability, breeding season, and habitat preference), that need to be taken into consideration when assessing the influence of forest fragmentation on carabid assemblages (reviewed by Niemelä, 2001). Davis and Margules (1998) found that habitat fragmentation did not alter species richness, although the abundance of some species increased or decreased. This is because open-habitat species (generalist species) invade fragmented forest from the surrounding habitats, where species richness 
is higher. Furthermore, our studied forest fragments are relatively small [1.63 \pm 0.53 ha (mean \pm S.D.) $]$. Small-sized fragments have more open and grassier habitat, and are thus more favorable for the carabid species primarily residing in the surrounding grasslands (Niemelä, 1988; Halme and Niemelä, 1993).

Forest species tend to prefer cooler temperatures and higher humidity. Closed canopies act as windbreaks and sources of shade that moderate ground surface conditions. Removal of the canopy results in increased insolation, greater temperature fluctuation, and a drier environment. As the mature forest and/or older forest increase in resources and heterogeneity, they seem to support more large-sized carabid beetles. Many studies have confirmed an increase in carabid species size with habitat stability. Small-sized species develop faster and have shorter generation times (Peters, 1983; Blake et al., 1994), whereas large-sized carabid beetles have longer developmental periods that can be supported in stable habitats with sufficient resources (Peters, 1983).

The ordination results showed that understorey environment, including sub-tree and shrub cover, plays an important role in structuring the carabid assemblages. Managed forest and forest fragment have different species composition of carabid beetles compared with native forest habitat because the carabid assemblage is mainly structured by management of the canopy tree or understorey vegetation layer (Ings and Hartley, 1999; Jukes et al., 2001; Taboada et al., 2006).

In our study, managed forest habitats are very similar to dehesa forest and/or mature open forest type due to the regular mowing, harvesting of grass, and planting of trees for landscape architecture. Species diversity is at its greatest in the more open forest because the open spaces within conifer forests provide a suitable habitat for many generalist species (Day et al., 1993; Jukes et al., 2001). In this study, however, we found that managed forest habitats had the lowest carabid richness and abundance. Furthermore, forest management practices, particularly clear-cutting of the understorey, significantly influences carabid richness and abundance. Grass cutting is a catastrophic process, where the vegetation undergoes a rapid structural change (Morris and Rispin, 1988; Morris 2000). Some species experience severe mechanical stresses and may be killed by the cutting operation itself. Moreover, such cutting dramatically changes the physical structure of the environment, as well as temperature, humidity, food availability, and predation pressure (reviewed by Humbert et al., 2009). Carabid beetle assemblages are also changed in relation to cutting intensity (Haysom et al., 2004).

Of course, maintaining the vegetation composition may not be the only crucial determinant of carabid beetle species richness (Lövei and Cartellien, 2000). Vegetation structure and diversity was insufficient to maintain a potential carabid assemblage in forest fragments and managed forest. However, efforts to reduce artificial disturbance such as logging and clear-cutting of the understorey are necessary for conserving the many forest species. Further, these efforts may maintain and improve the habitat heterogeneity in disturbed habitats that support potential carabid communities (Niemelä et al., 1996; Do et al., 2011). In the present study, we found that forest fragments still retain the carabid beetle characteristic of closed canopy montane forests. Forest patches should be connected with one another and with native forests. Creation of windbreaks and hedgerows might seem a reasonable solution because several studies have demonstrated that forest carabid beetles, particularly forest specialists, can migrate by using windbreaks and hedgerows as forest corridors (Magura et al., 2000; Dyck and Baguette, 2005). 


\section{REFERENCES}

[1] Andrén, H. (1997): Habitat fragmentation and changes in biodiversity. - Ecol. Bull. 46: 171-181.

[2] Blake, S., Foster, G.N., Eyre, M.D., Luff, M.L. (1994): Effects of habitat type and grassland management practices on the body size distribution of carabid beetle. Pedobiologia 38: 502-512.

[3] Davies, K.F., Margules, C.R. (1998): Effects of habitat fragmentation on carabid beetles: experimental evidence. - J. Anim. Ecol. 67: 460-471.

[4] Day, K.R., Marshall, S., Heaney, C. (1993): Associations between forest type and invertebrates: ground beetle community patterns in a natural oakwood and juxtaposed conifer plantations. - Forestry 66: 37-50.

[5] Didham, R.K., Ghazoul, J., Stork, N.E., Davis, A.J. (1996): Insert in fragmented forest: a functional approach. - Trends Ecol. Evol. 11: 255-260.

[6] Do, Y., Jeong, K.S., Lineman, M., Kim, J.Y., Kim, H.A., Joo G.J. (2011): Community changes in carabid beetles (Coleoptera: Carabidae) through ecological succession in abandoned paddy fields. - Ecol. Field Biol. 34: 269-278.

[7] Do, Y., Moon, T.Y. (2002): Succession of insect communities by desiccation of bog Hwaemneup at Mt. Wonhyosan, Yangsan. - J. Korean Wetl. Soc. 4: 13-22. (in Korean with English summary).

[8] Do, Y.N., Moon, T.Y., Joo, G.J. (2007): Application of the carabid beetles as ecological indicator species for wetland characterization and monitoring in Busan and Gyeongsangnam-do. - Korean J. Environ. Ecol. 21: 22-29. (in Korean with English summary).

[9] Fahrig, L. (2003): Effects of habitat fragmentation on biodiversity. - Annu. Rev. Ecol. Evol. S. 34: 487-515.

[10] Fox, J. (2005): R commander-a platform-independent basic statistics GUI (graphical user interface) for R. - J. Stat. Softw. 14: 9.

[11] Halme, E., Niemelä, J. (1993): Carabid beetles in fragments of coniferous forest. - Ann. Zool. Fenn. 30: 17-30.

[12] Hanski, I. (1999): Habitat connectivity, habitat continuity, and metapopulation in dynamic landscapes. - Oikos 87: 209-219.

[13] Haysom, K.A., McCracken, D.I., Foster, G.N., Sotherton, N.W. (2004): Developing grassland conservation headlands: response of carabid assemblage to different cutting regimes in a silage field edge. - Agric. Ecosyst. Environ. 102: 263-277.

[14] Humbert, J.Y., Ghazoul, J., Walter, T. (2009): Meadow harvesting techniques and their impacts on field fauna. - Agric. Ecosyst. Environ. 130: 1-8.

[15] Ings, T.C., Hartley, S.E. (1999): The effect of habitat structure on carabid communities during the regeneration of native Scottish forest. - For. Eco. Manage. 119: 123-136.

[16] Jongman, R., ter Braak, C.J.F., van Tongeren, O. (1995): Data analysis in community and landscape ecology. - Cambridge University Press, pp 324.

[17] Jukes, M.R., Peace, A.J., Ferris, R. (2001): Carabid beetle communities associated with coniferous plantation in Britain: the influence of site, ground vegetation and stand structure. - For. Eco. Manage. 148: 271-286.

[18] Kimmins, J.P. (1997): Forest ecology: a foundation for sustainable management (2nd edit). Prentice Hall. pp 596.

[19] Lövei, G.L., Cartellieri, M. (2000): Ground beetle (Coleoptera, Carabidae) in forest fragments of the Manawatu, New Zealand: Collapsed assemblages? - J. Insect. Conserv. 4: $239-244$.

[20] Lövei, G.L., Magura, T., Tóthmérész, B. (2006): The influence of matrix and edges on species richness patterns of ground beetles (Coleoptera: Carabidae) in habitat islands. Global Eco. Biogeog. 15: 283-289. 
[21] Magura, T., Ködöböcz, V., Tóthmérész, B. (2001): Effects of habitat fragmentation on carabids in forest patches. - J. Biogeog. 28: 129-138.

[22] Magura, T., Tóthmérész, B., Bordán, Zs., (2000): Effect of nature management practice on carabid assemblages (Coleoptera: Carabidae) in a non-native plantation. - Biol. Conserv. 93: 95-102.

[23] McCune, B., Grace, J.B. (2002): Analysis of ecological communities. - MJM Software Design, Gleneden Beach, Oregon, pp 300.

[24] Morris, M.G, Rispin, W.E. (1988): A beetle fauna of oolithic limestone grassland, and the responses of species to conservation management by different cutting regimes. - Bio. Conserv. 43: 87-105.

[25] Morris, M.G. (2000): The effects of structure and its dynamics on the ecology and conservation of arthropods in British grassland. - Bio. Conserv. 95: 129-142.

[26] Niemelä, J. (2001): Carabid beetles (Coleoptera: Carabidae) and habitat fragmentation: a review. - Eur. J. Entomol. 98: 127-130.

[27] Niemelä, J., Haila, Y., Halme, E., Lahti, T., Pajunen, T., Punttila, P. (1988): The distribution of carabid beetles in fragments of old coniferous taiga and adjacent managed forest. - Ann. Zool. Fenn. 25: 107-119.

[28] Niemelä, J., Haila, Y., Punttila, P. (1996): The importance of small-scale heterogeneity in boreal forests: variation in diversity in forest-floor invertebrates across the succession gradient. - Ecography 19: 352-368.

[29] Park, J.K., Paik, J.C. (2001): Economic insects of Korea 12-Insecta Koreana suppl. 19: Coleoptera (Carabidae). - National Institute of Agricultural Science and Technology. pp 169.

[30] Pearce, J., Venier, L.A. (2006): The use of ground beetles (Coleoptera: Carabidae) and spiders (Aranease) as bioindicators of sustainable forest management: a review. - Eco. Indic. 6: 780-793.

[31] Peters, R.H. (1983): The ecological implications of body size. - Cambridge University Press, Cambridge, pp 344.

[32] Pirnat, J. (2001): Conservation management of forest patches and corridors in suburban landscapes. - Landscape Urban Plan. 52: 135-143.

[33] Raino, J., Niemelä, J. (2003): Ground beetles (Coleoptera: Carabidae) as bioindicators. Biodiv. Conserv. 12: 487-506.

[34] Taboada, A., Kotze, D.J., Tárrega, R., Salgado J.M. (2006): Traditional forest management: do carabid beetles respond to human-created vegetation structures in an oak mosaic landscape? - For. Eco. Manage. 237: 436-449.

[35] ter Braak, C., Šmilauer, P. (2002): CANOCO reference manual and and CanoDraw for user's guide to Canoco for Windows: software for canonical community ordination (version 4.5). - Microcomputer Power, Ithaca, New York, pp 500.

[36] Tyrväinen, L., Silvennoinen, H., Kolehmainen, O. (2003): Ecological and aesthetic values in urban forest management. - UFUG 1: 135-149.

[37] van Dyck, H., Baguette, M. (2005): Dispersal behavior in fragmented landscapes: routine or special movements? - Basic and Appl. Ecol. 6: 535-545.

[38] Waring, R.H., Schlesinger, W.H. (1985): Forest ecosystems. Concepts and management, 3rd edit. - Academic Press, New York, pp 340.

[39] Working group for biological indicator ground beetles database, Japan. (2010): Natural woodland ground beetles. - http://www.lbm.go.jp/emuseum/zukan/gomimushi/english/ index.html. Accessed 15 September 2011. 